\title{
Exposure to Secondhand Tobacco Smoke Among Tertiary Institution Students of Apa Local Government Area of Benue State Nigeria: A Menace to Future Dilemma of Cigarette Complications
}

\author{
Audu Onyemocho \\ Department of Epidemiology and Community Health \\ College of Health Sciences, Benue State University \\ Makurdi, Benue State, Nigeria \\ Anejo-Okopi Joseph Aje \\ AIDS Prevention Initiative in Nigeria \\ Jos University Teaching Hospital, Jos, Nigeria \\ Ogboi Sonny Johnbull \\ Malaria \& Human Development \\ Department of Life Sciences and Public Health \\ University of Camerio, 62032 Camerio (MC), Italy \\ Mbaave Tsavyange Peter \\ Department of Internal Medicine \\ Benue State University, Makurdi, Nigeria \\ Igbudu Terhemen Joseph \\ Department of Family Medicine \\ Benue State University Teaching Hospital \\ Makurdi, Benue State, Nigeria
}

\begin{abstract}
Background: Nigeria is one of the top ten countries in low and middle income countries where young adults are more exposed to secondhand smoke but the tobacco control policy is inadequate. This study assessed the prevalence and the correlates of secondhand smoke among young educated elites of APA local government area of Benue State, Nigeria. Materials and Methods: A crosssectional study was carried out during the youth annual week programme with the team entitled "ingredients of a successful career "from 4th -8th January 2014. Inclusion was strictly based on the membership of the local government council elite youth association. Structured self-administered questionnaire was employed. Information obtained includes: Socio-demographic information; cigarrete smoking and pattern of exposure to tobacco smoke in the previous 30 days before the survey. Data was analyzed using SPSS version 20.0. Multiple logistic regressions were performed to test relationship between the predictor variables and the outcome variable (secondhand smoke), by controlling for possible cofounders. Results: The mean age of the educated elites was 25.8years ( $S D= \pm 5.8$ years), $84(20.7 \%)$ had history of smoking in the past, while $55(13.6 \%)$ are currently smoking. Forty- three percent of respondents were aware of the harmful effects of SHS on their health. Overall, $49.0 \%$ of them were
\end{abstract}


exposed to SHS at Bars/restaurants, $25.2 \%$ ) \% in football viewing centre, and $\mathbf{1 1 . 5 \%}$ in the home. Marital status, religion, and respondents past and current smoking status were among the significant determinates, whereas, parental and close friends smoking status were not significant $(p=0.118$ and $p=0.236$ respectively). Conclusion: Our results show that prevalence of SHS exposure was highest in public places. These findings underscore the need for enactment of comprehensive smoke-free legislation and implementation of educational strategies to reduce SHS exposure in homes.

Keywords: Secondhand Tobacco Smoke, educated elites, correlates, Benue, Nigeria.

\section{INTRODUCTION}

Globally, tobacco use is one of the leading and preventable causes of morbidities and mortalities including cancer and cardiovascular diseases annually [1]. However, it is not only smokers that suffers the negative impact of smoking as evidence shows that for every eight smokers who die from smoking, one nonsmoker also dies from secondhand smoke [2]. Secondhand smoke in this regard refers to the tobacco smoke that is exhaled by a smoker or is given off by burning tobacco and is inhaled by persons nearby [3,4]. Over the years, while the developed world are experiencing a decrease in the trend of tobacco consumption, the developing countries on the order hand have experienced either a stationary or increasing trend, thereby resulting to increased global prevalence [5, 6] In 2013 alone, the global mortality and economic damage due to tobacco epidemic was estimated to be 6 million and half a trillion dollar respectively and most of these problems are noted in low-and-medium income countries $[7,8]$.

The epidemic increase of tobacco consumption either as smokers or secondhand smoker in the low income countries like Nigeria will lead to major public health issues of concern as some of these countries are already faced with considerable challenges of fighting poverty, emerging and re-emerging diseases, security insurgence and political crises $[9,10]$. It will also affect the economic growth and sustainable development of these countries [11,12, and 13]

The Global Adult Tobacco Survey(GATS) done in Nigeria in 2012 revealed that among adults who had visited public places in the last thirty days preceding the survey, almost one out of every three were exposed to second hand smoke in restaurants; one out of every six in government buildings; and one out of every twenty in health care facilities. In that report, it was also indicated that, up to 18.4 million children are exposed to secondhand in their homes, while 27.6million are exposed in public spaces; making Nigeria one of the top ten countries in low and middle income countries where children are more exposed to secondhand smoke [14]. Interestingly up to $88.5 \%$ of Nigerian adults surveyed in the GATS favored increasing taxes on tobacco products. This shows that the citizenry are tired of the weak unenforceable regulations on tobacco products in Nigeria [14].

WHO is committed to fighting the global tobacco epidemic? The WHO Framework Convention on Tobacco Control entered into force in February 2005. Since then, it has become one of the most widely embraced treaties in the history of the United Nations with 178 Parties covering $89 \%$ of the world's population [7]. There has been some interest from the ministry of health to enact tobacco control legislations in order to domesticate the WHO's Framework Convention on Tobacco Control (FCTC) in Nigeria, but the Nigerian legislators are yet to show the prove as cigarrete smoking still abounds in places of work, offices, restaurants and individual homes. States like Lagos made attempts at making comprehensive law to regulate the manufacturing, advertising distribution and consumption of tobacco products in Lagos [15], but such laws or attempts have never been made in Benue state. That is to say; currently, there are no 
operational legislations protecting youths from obtaining tobacco products in Nigeria. In addition, there are no regulations banning some or all types of tobacco advertisement, promotion and sponsorship. However, the onset of tobacco use occurs primarily in early adolescence [14]. Young people are influenced by what they see than what they are told. It is obvious that the deceptive incentive of tobacco industries and peer pressure have influenced young people to engage in smoking as $18.9 \%$ of Nigerian youths have been reported to smoke cigarrete at less than 15 years of age [14]. By implication young Nigerians will become daily cigarrete users and secondhand smokers before they could comprehend the adverse effect of cigarrete smoking if nothing is done in terms of their behavioral changes. This study assessed the prevalence and the correlates of secondhand smoking among young educated elites of APA local government area of Benue State, Nigeria in order to add to the sparse literature on tobacco usage among boys and girls in the Benue as to provide feasible intervention approach to mitigating the effect of smoking and secondhand smoke among youths.

\section{METHODOLOGY}

\section{Study area}

Apa Local Government Area (LGA) was created in 1991 by the then military head of State of Nigeria, General Ibrahim Badamosi Babangida; covering what was the old Ochekwu district of Otukpo division. It is one of the 9 local government areas in the southern senatorial zone which is majorly occupied by the Idoma people of Benue State. The LGA is made up 84 villages, (settlements), 18 clans, 11 district wards. The major big villages includes Ugboko (the headquarter), Oiji, Ojantele, Akpete, Iga-Okpaya, Ikobi, Odugbo, Ofoke, Oba Alifeti, Idada, Edikwu-Icho, Ugbobi, Ebugodo, Opaha. The LGA shares boundary with Agatu, Otukpo and Gwer West local government areas of Benue State to her north, south and east respectively, while to her west, she is bordered by Ankpa and Omala local government areas of Kogi State. The LGA has an estimated population of 790,454(2006 population census). About 257, 644 $(32.6 \%)$ of the estimated population are youths between 15-25 years of age. The people of the local government area predominantly speak a dialect of Idoma language and majority of them are peasant farmers. All the villages in the LGA has at least a beer pallor where people who drink alcoholic beverages (beer) stay and drink, especially in the evenings after the closing of the days farming activities. Each of the village has at least a primary school where pupils are trained and some have secondary schools. At the period of the survey, about 6,000 youths were in different tertiary institutions of learning across Nigeria and abroad. About 4234 of these youths from different villages registered with the LGA youth organization named "Apa Youth Association". The eligibility criteria was based on being an indigene of the local government by birth or if parents have stayed in the local government for over 10 years and being in any tertiary institution of learning. Majority of them were in Benue State University Makurdi, University of Agriculture Makurdi, and Benue State polytechnic Ugbokolo, College of education Katsina- Alla and College of education Oju, all situated in Benue state. Only few of the registered youths school in tertiary institutions outside the state. The LGA is selected for the study because it is centrally located in the Idoma speaking communities of the state and is represented fairly by a cross section of other tribes because of its boundary.

\section{Study Design and Study Participants}

A community based cross-sectional descriptive study design was employed for the study from 4th to 8th January 2014 at APA Youths Association annual seminar/youth enlightenment campaign week. During the period of the study, the LGA council youths were holding a week programme with the team entitled "ingredients of a successful career". The study captured all the registered youth attendees. By the association criteria and definition, a youth is strictly on the basis of admission in higher institutions of learning, irrespective of the age. 


\section{Sample Size Estimation and sampling technique}

A minimum sample size of 345 was arrived at using the formula

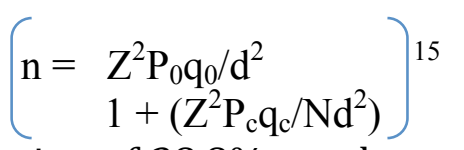

With assumption of $38.8 \%$ youths exposed to secondhand smoke from a previous study [16] and $5 \%$ tolerable margin of error at $95 \%$ confidence interval. Considering drop-out rate of $15 \%$ the calculated sample size was adjusted to 405 . Simple random sampling technique was used for the study. The list of all the registered members was obtained from the general secretary's office and used as the sampling frame. Registered youth who were not in any higher institution of learning at the time the study was conducted were excluded from the study. Registered members who did not attend the youth week programme and those who were in attendant but did not consent to the study were also excluded from the study.

\section{Instrument for data collection}

Structured self-administered questionnaire was employed for data collection. Information obtained includes: Socio-demographic information; cigarrete smoking and pattern of exposure to tobacco smoke in the previous 30 days before the survey.

\section{DATA ANALYSIS}

All analyses were conducted using the Statistical Package for Social Sciences (SPSS) version 20. Information's sorted were categorized, summarized and presented in exploratory formats as frequency tables, figures and graphs. Chi-square $(\chi 2)$ test was used for test of association between the sociodemographic variables and the main outcome of the study, with statistical significance set at $P$ value of 0.05 . Linear relationship between the predictor variables and secondhand smoking (criterion variable) was further performed for the independent predictors that have significant chi-square, using linear logistic regression models by controlling for possible confounders.

\section{Ethical Issues}

Ethical approval for the study was obtained from the health research ethic committee of Benue University Hospital (BSUTH) Makurdi, before the study was conducted. An informed written consent was also obtained from APA LGA council chairman and the chairman of Apa Youth Association. The consent of all the respondents was also soughed. .

\section{Sociodemographic characteristics}

\section{RESULTS}

All the eligible respondents who consented to the interview completed the questionnaires correctly and returned them giving a response rate of 100\%. Table 1 summarises the sociodemographic charteristics of the respondents. The age of the respondents ranges from 17- 42 years, with mean age of 25.8years (SD \pm 5.8 years). The respondents were predominantly male $(83.7 \%)$, with male to female ratio of $5: 1$. Majority $(70.1 \%)$ of them were in the University, followed by those in the Polytechnics (24.7\%), while the least proportion of the respondents were those in Colleges of Education (5.2\%). Above two-third (70.1\%) were single at the time of survey, while $21.7 \%$ and $8.1 \%$ were marriage and separated/widowed respectively. The predominant religion of the respondents was Christianity $(89.1 \%)$. 
Table 1: Sociodemographic characteristics of Respondents $(n=405)$

\begin{tabular}{|cc|}
\hline Variable & Frequency (\%) \\
\hline Age group (Years) & \\
$\leq 19$ & $52(12.8)$ \\
$20-29$ & $269(66.4)$ \\
$30-39$ & $65(16.0)$ \\
$\geq 40$ & $19(4.7)$ \\
Sex & \\
Male & $339(83.7)$ \\
Female & $66(16.3)$ \\
University & \\
Polytechnic & $284(70.1)$ \\
College of Education & $100(24.7)$ \\
Marital status & $21(5.2)$ \\
Single & \\
Married & $284(70.1)$ \\
Religion & $88(21.7)$ \\
Christianity & $33(8.1)$ \\
Muslim & $362(89.4)$ \\
Separated /Divorced/Widowed & $44(10.6)$ \\
\hline
\end{tabular}

Mean age: $25.8(\mathrm{SD}= \pm 5.8$ years $)$

\section{Respondents, family and friends smoking status}

Table 2 summarises the respondent's self, family and friends history of smoking by sex and location. Of all, 84(20.7\%) had past history of smoking, while $55(13.6 \%)$ are currently smoking. Male to female ratio of those who had ever smoked was $7.4: 1$. Majority (44.6\%) of them had their first cigarrete smoking experience when they were between 20-24 years, with mean age of 21.6 years (SD \pm 3.2 years). Twenty four $(52.2 \%)$ male reported smoking in public places as against $6(66.7 \%)$ female. Overall, $317(78.3 \%)$ do not have family history of smoking. Among the respondents with positive family history of smoking, those whose wives or husbands smoke constitutes the highest proportion (59.1\%), followed by those whose parent's smokes (25.0\%). Majority (71.1\%) of the respondents friends do not smoke.

Table 2: Summary of history of smoking by sex of respondents

\begin{tabular}{|cccc|}
\hline $\begin{array}{c}\text { Variable } \\
\text { Ever smoked }\end{array}$ & $\begin{array}{c}\text { Male } \\
\text { Frequency (\%) }\end{array}$ & $\begin{array}{c}\text { Female } \\
\text { Frequency (\%) }\end{array}$ & Total (\%) \\
\hline Yes & $74(21.8)$ & $10(15.2)$ & $84(20.7)$ \\
No & $265(78.2)$ & $56(84.8)$ & $321(79.3)$ \\
Age at First smoke(n=74) & & & \\
$\leq 14$ & $4(6.3)$ & $0(0.0)$ & $4(5.4)$ \\
$15-19$ & $15(23.4)$ & $1(10.0)$ & $16(21.6)$ \\
$20-24$ & $27(42.2)$ & $6(60.0)$ & $33(44.6)$ \\
$\geq 25$ & $1828.1)$ & $3(30.0)$ & $21(28.4)$ \\
Currently smoking & & & \\
Yes & $46(13.6)$ & $9(13.6)$ & $55(13.6)$ \\
No & $293(86.4)$ & $57(86.5)$ & $350(86.4)$ \\
Place of smoking & & & \\
Public places & $24(52.2)$ & $6(66.7)$ & $30(54.5)$ \\
Home & $14(30.4)$ & $3(33.3)$ & $17(30.9)$ \\
Public and private & $8(17.4)$ & $0(0.0)$ & $8((14.5)$ \\
\hline
\end{tabular}


Family smoking
Yes

No

Family member who smoked

Spouse
Siblings

Parents

Friends smoking

Yes

No
$66(19.5)$

273(80.5)

$30(57.7)$

14(26.9)

$8(15.4)$

$97(28.6)$

242(71.4)
22(33.3)

44(66.7)

22(61.1)

$8(22.2)$

$6(16.7)$

$20(30.3)$

46(69.7)
$88(21.7)$

$317(78.3)$

$52(59.1)$

$22(25.0)$

$14(15.9)$

$117(28.9)$

288(71.1)

Mean age at first smoking 21.6 years (SD \pm 3.2 years).

\section{Awareness of harmful effects of secondhand smoking}

A total of $172(42.5 \%)$ respondents reported that the tobacco smoke that is exhaled by a smoker or is given off by burning tobacco and is inhaled by persons nearby could have adverse health effect on the person who inhaled the smoke, while $28.1 \%$ cited that second hand smoking has no health implication on those who do not smoke and $29.4 \%$ were not sure of the health implications. Regarding the diseases associated with smoke, respiratory tract infection and cancer of the lungs were the only disease mentioned (70.1\% and $8.1 \%$ respectively) (Figure 1).

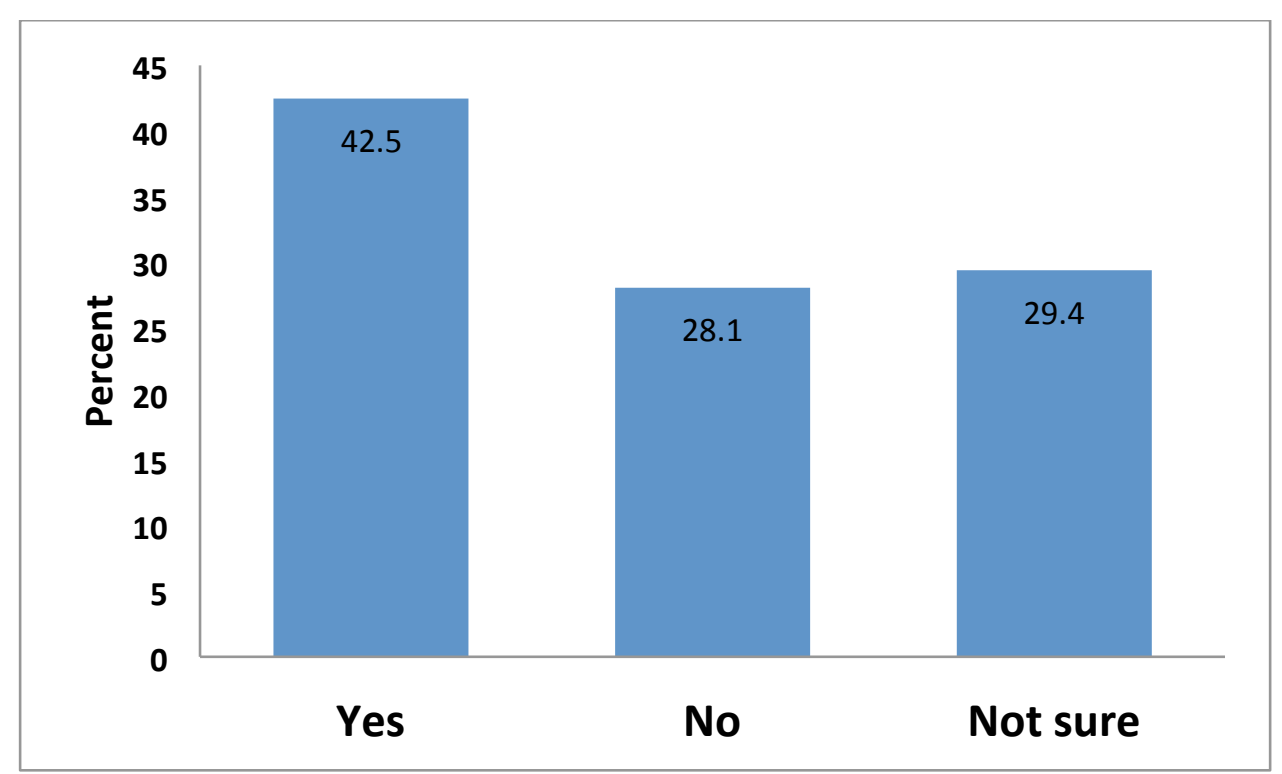

Figure 1: Awareness of harmful effects of exposure to secondhand smoke

\section{Prevalence of exposure to secondhand smoke}

Table 3 provides information on respondent's exposure to secondhand smoke 30 days before the study. Of the total, 286 (70.6\%) had exposure, while the remaining 119 (29.4\%) do not. Male to female ratio of the respondents exposed was aproximately11:1. Considering the prevalence by location of exposure, 125(47.0\%) of the male reported exposure in bar/restaurants, 68(26.0\%) reported in football viewing centers, 39(14.8\%) reported exposure at motor parks and or while using public transport and 30(11.5\%) reported exposure at home. Fifteen (62.5\%) female reported exposure in bar/restaurants, $4(16.7 \%)$ reported exposure in football viewing centers, 3 (12.5\%) reported exposure at home and $2(8.3 \%)$ reported exposure at motor parks and or while using public transport. The relationship between to exposure secondhand smoke, location and sex of respondents are statistically significant $(p=0.000)$. 
Onyemocho, A., Aje, A. O. J., Johnbull, O. S., Peter, M. T., \& Joseph, I. T. (2015). Exposure to secondhand tobacco smoke among Tertiary institution students of APA Local Government Area of Benue State Nigeria: A menace to future dilemma of Cigarette complications. Archives of Business Research, 3(4), 30-39.

Table 3: Prevalence of Secondhand smoke and Location by sex

\begin{tabular}{|cccc|}
\hline Secondhand smoke & Male & Female & Total \\
Yes & $262(77.3)$ & $24(36.4)$ & $286(70.6)$ \\
No & $77(22.7)$ & $42(63.6)$ & $119(29.4)$ \\
Location & $x^{2}=44.587 ; \mathrm{df}=1 ; \mathrm{p}=0.000$ & & \\
Bar/Restaurant & & & $140(49.0)$ \\
Football Viewing centre & $125(47.7)$ & $15(62.5)$ & $72(25.2)$ \\
Motor park/public transport & $68(26.0)$ & $4(16.7)$ & $41(14.3)$ \\
Home & $39(14.8)$ & $2(8.3)$ & $33(11.5)$ \\
& $30(11.5)$ & $3(12.5)$ & \\
\hline
\end{tabular}

Correlates of exposure to secondhand smoke

Table 4 explores the relationship between the independent variables (predictors) and the outcome (secondhand smoke). The relationship between all the sociodemographic variables (except age of respondents) and the outcome are statistically significant $(\mathrm{p}<0.005)$.

Table 5 is the linear multiple regression of the predictors that has significant $\chi 2$. Using the enter method, a significant model emerged (F8, 229 $=69.132$, $\mathrm{p}<0.0005$, and Adjusted R Square $=0.8642$ ). Significant variables are sex, marital status, religion, ever smoked and currently smoking. Marital status, had higher impact (Beta $=1.038)$ on SHS as compared to the other predictors, followed by ever smoked $($ Beta $=0.255)$, sex $($ Beta $=0.111)$ religion $($ Beta $=-0.280)$ and currently smoking (Beta $=$ - 0.117). Exposure to SHS among single/separated/divorced/widow men was significantly more likely as compared to married men and women (Beta= 1.038). Age at first smoking, immediate family member smoking, and friends smoking do not have a significant impact on exposure secondhand smoke

Table 4: Sociodemographic variables by exposure to secondhand smoking among respondents

\begin{tabular}{|c|c|c|c|c|}
\hline \multirow[t]{2}{*}{ Variable } & \multicolumn{3}{|c|}{ Exposure to Secondhand smoking } & \multirow[t]{2}{*}{ p-value } \\
\hline & $\begin{array}{c}\text { Yes } \\
\text { n(\%) }\end{array}$ & $\begin{array}{c}\text { No } \\
\text { n(\%) } \\
\end{array}$ & $\begin{array}{l}\text { Total } \\
\mathbf{n}(\%)\end{array}$ & \\
\hline \multicolumn{5}{|l|}{ Age (years) } \\
\hline$\leq 19$ & $38(13.3)$ & $14(11.8)$ & $52(12.8)$ & \\
\hline $20-29$ & $190(66.4)$ & $79(66.4)$ & $269(66.4)$ & \\
\hline $30-39$ & $45(15.7)$ & $20(16.8)$ & $65(16.0)$ & \\
\hline$\geq 40$ & $13(4.5)$ & $6(5.0)$ & $19(4.7)$ & 0.968 \\
\hline \multicolumn{5}{|l|}{ Sex } \\
\hline Male & $262(91.6)$ & $77(64.7)$ & $339(83.7)$ & \\
\hline Female & $24(8.4)$ & $42(35.3)$ & $66(16.3)$ & 0.000 \\
\hline \multicolumn{5}{|l|}{ Marital status } \\
\hline Single & $218(73.9)$ & $66(60.0)$ & $284(70.1)$ & \\
\hline Married & $66(22.4)$ & $22(20.0)$ & $88(21.7)$ & \\
\hline Separated /Divorced/Widowed & $11(3.7)$ & $22(20.0)$ & $3398.1)$ & 0.000 \\
\hline \multicolumn{5}{|l|}{ Religion } \\
\hline Christianity & $286(100.0)$ & $76(63.9)$ & $362(89.4)$ & \\
\hline Islam & $0(0.0)$ & $43(36.1)$ & $43(10.6)$ & 0.000 \\
\hline
\end{tabular}


Ever smoked

\begin{tabular}{lcccc} 
Yes & $82(28.7)$ & $2(1.7)$ & $84(20.7)$ & \\
No & $204(71.3)$ & $117(98.3)$ & $321(79.3)$ & 0.000 \\
member smoked & & & & \\
Yes & $88(30.8)$ & $0(0.0)$ & $88(21.7)$ & \\
No & $198(69.2)$ & $119(100.0)$ & $317(78.3)$ & 0.000 \\
\hline
\end{tabular}

Table 5: Multiple linear regression

\begin{tabular}{|c|c|c|}
\hline \multirow[t]{2}{*}{ Predator Variable } & \multicolumn{2}{|c|}{ Dependent Variable: Secondhand smoking } \\
\hline & Beta & p value \\
\hline Sex & .111 & $\mathrm{p}<0.005$ \\
\hline Marital Status & 1.038 & $\mathrm{p}<0.005$ \\
\hline Religion & -.280 & $\mathrm{p}<0.005$ \\
\hline Ever smoked & .255 & $\mathrm{p}<0.005$ \\
\hline Age at first smoking & -.003 & $\mathrm{p}=0.889$ \\
\hline Currently smoking & -.117 & $\mathrm{p}<0.005$ \\
\hline Family smoked & -.081 & $\mathrm{p}=0.118$ \\
\hline Friends smoked & .043 & $\mathrm{p}=0.236$ \\
\hline
\end{tabular}

\section{DISCUSSION}

Our study has attempted to explore the burden of secondhand tobacco smoke and cigarette smoking among young educated elites in a local government council in Nigeria and the likely threat it poses on their health. The overall sociodemographic charteristics of the study population depicts that of a typical Nigerian tertiary institution. By implication, majority of the elites are young people who can easily be influenced by what they see than what they are told.

In our study, the prevalence of smoking in the study population was $20.7 \%$, and the mean age at commencement of smoking was 21.6 years ( \pm 3.2 years). Our findings are consistent with the national prevalence [14]. The probably reason behind the findings could be due to the age of the participants and their educational status. It is obvious that since the participants are students in the tertiary institutions there could be deceptive incentive of tobacco industries in terms of promotion on campuses which may inform their decision on smoking behaviour. Furthermore, peer pressure from friends may have influenced the study population to engage in smoking.

Regarding SHS, the overall prevalence in our study was $70.6 \%$, with male to female ratio of 11:1. The prevalence of SHS found in our study is higher when compared to other studies in Nigeria [16], South Africa [17] Cambodia [18], and China [19] that adopted similar methodology. It is consistent with the prevalence of $68 \%$ reported for a study conducted for Seoul city of South Korea [20] and 70\% reported for Spain [21]. Majority of exposure to SHS occurs in public places (bars/restaurants, football viewing centre, motor parks or public transports). Also in this study $42.5 \%$ of the young elites are aware of the harmful effects of exposure to SHS. Despite the significant level of awareness on the harmful effects, exposure to SHS was still high. This may be attributed to the student's low level of awareness on ban on smoking in public places. By implication young elites in APA local government area of Benue State Nigeria, will become cigarrete smokers and secondhand smokers before they could comprehend the adverse effect of cigarrete smoking if nothing is done in terms of their behavioral changes.

Our study found in multivariate analysis that sex, marital status, religion and personal experience of cigarette smoking, were significant determinants of young elites to exposure to 
both SHS at home and outside of the home. Marital status, had higher impact (Beta=1.038) on SHS exposure among the students studied. This is contrary to study by Desalau et al where parental, close friends smoking status, allowing someone to smoke around you and perception that passive smoking is harmful were the main significant determinants of adolescent's exposure to both SHS at home and outside of the home[22]. The impact of marital status on SHS in our study could be due to high proportion of singles and the separated or divorced young elites in the study. Since majority of the SHS take place outside the homes, it's possible that the singles or the separated/divorced young elites who may probably have more time staying in public places with friends are more likely to be exposed to SHS. By implication, if the young elites are not properly educated on effects of smoking in public places and or educated on the dangers of SHS, they stand a chance of manifesting with harmful effects of SHS at older ages in life.

Conclusion: The prevalence of smoking and exposure to SHS among the young educated elites of APA LGA, Benue state Nigeria was high and majority of the exposure occur in public places. These findings underscore the need for enactment of comprehensive smoke-free legislation and implementation of educational strategies to reduce SHS exposure in public places.

\section{Conflict of Interests}

The authors declare that there is no conflict of interests regarding the publication of this paper.

\section{References}

USDHHS. Preventing tobacco use among youth and young adults: A report of the surgeon general. (Accessed on 27th March, 2014 at http://www.surgeongeneral.gov/library/reports/preventing-youth-tobacco-use/full-report.pdf.)

CDC. Fact sheet-Secondhand smoke facts (Accessed on 6th Dec. 2014 at

www.cdc.gov/tobacco/data_statistics/../secondhand_smoke/general)

Institute of Medicine. Secondhand Smoke Exposure and Cardiovascular Effects: Making Sense of the Evidence [PDF707.47 KB]. Washington: National Academy of Sciences, Institute of Medicine, 2009 [accessed 2015 Feb 5]

National Toxicology Program. Report on Carcinogens, Thirteenth Edition. Research Triangle Park (NC): U.S. Department of Health and Human Services, National Institute of Environmental Health Sciences, National Toxicology Program, 2014 [accessed 2015 Feb 5].

USDHHS. Trends in Adolescent Tobacco use: A report of the office of Adolescent Health (Accessed at www.hhs.gov on 4th January, 2015).

Johnston LD, O'Malley PM, Bachman JG, Schulenberg JE. Monitoring the Future national survey results on adolescent drug use: Overview of key findings, 2013. Ann Arbor: Institute for Social Research, the University of Michigan, 2014.

WHO. WHO report about Global Tobacco Epidemic, 2013, enforcing bans on tobacco advertising, promotion and sponsorship? World Health Organization, Geneva, Switzerland. 2013

Tanimola Akande: The national chairman, Association of Public Health Physicians of Nigeria (APHPN), speech at a press conference to mark the "World No Tobacco Day" in Ilorin, Kwara State, Nigeria 2014.

Danaei G, Vander Hoorn S, Lopez AD, Murray CJL, Ezzati M. Causes of cancer in the world - comparative risk assessment of nine behavioral and environmental risk factors. The Lancet. 2005; 366(9499): $1784-1793$

Mufunda J, Chatora R, Ndambakuwa Y, Nyarango P, Chifamba J, Kosia A, Sparks HV. Prevalence of noncommunicable diseases in Zimbabwe - results from analysis of data from the National Central Registry and Urban Survey 2. Ethnicity and Disease. 2006; 16(3): 718-722

Conflict and spread of emerging infectious diseases (accessed at www.academicjournals.org//article1380378176_okonko\%20et\%20al on 13th December, 2014). 
African Progress Panel. An agenda for progress at a time of global crisis, a call for African Leadership, Annual Report of the African Progress Panel, 2009. (Accessed at www.africaprogresspanel.org//2009 on 6th May, 2013).

Alex E, Bruce J, David S. Confronting the Long Crisis of Globalization, Risk, Resilience and International Order. Managing global Insecurity bookings, 2001 (Available at www.bookings.edu//1.../01_globalization_evans_jones_stevene.pdf on 1st Jan. 2013).

Nigeria FMOH, WHO, CDC. Global Adult Tobacco Survey (GATS): Country Report, 2012. World Health Organization, Geneva, Switzerland, 2012.

Singa P. Introductive test on Biostatistics. Abdullahi Bello, Debco Investments Itd, Kaduna, 3rd Edn, 2002. Pg 203-207.

Olufemi OD, Cajetan CO, Olufemi OA, Ademola EF, Alakija KS. Secondhand smoke exposure among nonsmokingadults in two Nigerian cities. Annals of African Medicine, 2011; Vol. 10: 103-111

Karl P. Determinants of Exposure to Second-Hand Tobacco Smoke (SHS) among Current Non-Smoking In-School Adolescents (aged 11-18 years) in South Africa: Results from the 2008 GYTS Study. Int. J. Environ. Res. Public Health $2011,8,3553-3561$.

Rudatsikira EM, Knutsen SF, Job JS, Singh PN, Yel D, Montgomery SB, et al. Exposure to Environmental Tobacco Smoke in the Nonsmoking Population of Cambodia. Am J Prev Med 2008; 34:69-73?

Wang CP, Ma SJ, Xu XF, Wang JF, Mei CZ, Yang GH. The prevalence of household second-hand smoke exposure and its correlated factors in six counties of China. Tob Control 2009; 18:121-6.

Hughes SC, Corcos IA, Hofstetter CR, Hovell MF, Seo DC, Irvin VL, et al. Secondhand smoke exposure among nonsmoking adults in Seoul, Korea. Asian Pac J Cancer Prev 2008; 9:247-52.

Twose J, Schiaffi no A, Garcia M, Marti M, Fernandez E. Prevalence of exposure to environmental tobacco smoke in an urban population. Med Clin (Barc) 2004; 123:496-8.

Desalu OO, Oluboyo PO, Olokoba AB, Adekoya AO, Danburam A, Salawu FK, et al. Prevalence and determinant of tobacco smoking among HIV patients in North Eastern Nigeria. Afr J Med Med Sci 2009; 38:103-8. 